\section{Case Reports in Ophthalmology}

Case Rep Ophthalmol 2020;11:293-298

DOI: $10.1159 / 000508390$

Published online: July 6, 2020
(C) 2020 The Author(s)

Published by S. Karger AG, Basel www.karger.com/cop

\title{
Lens-Induced Uveitis Triggered by Intravitreal Injection 40 Years after Primary Congenital Cataract Surgery with Aphakia
}

\author{
Sophia El Hamichi ${ }^{a, b}$ Rafael J. Aguilar ${ }^{a} \quad$ Veronica Kon Graversen ${ }^{a}$ \\ Aaron S. Gold ${ }^{\mathrm{a}}$ Audina M. Berrocal ${ }^{\mathrm{b}}$ Timothy G. Murray ${ }^{\mathrm{a}}$ \\ aMiami Ocular Oncology and Retina, Miami, FL, USA; 'bepartment of Ophthalmology, \\ Bascom Palmer Eye Institute, University of Miami Miller School of Medicine, \\ Miami, FL, USA
}

\section{Keywords}

Congenital cataract · Phacoantigenic uveitis · Lens-induced uveitis · Intravitreal injection

\begin{abstract}
We report a case of a 42-year-old male with a history of bilateral congenital cataract surgery performed at 2 years of age. The patient was left with aphakia, secondary glaucoma, and a history of diabetic macular edema in the setting of diabetes mellitus type 1 . The right eye became prephthisical from his congenital surgical repair, and his left eye presented with an acute pseudo-endophthalmitis developing after the seventh intravitreal injection to treat the macular edema. The eye then presented with decrease in vision, periocular injection, and a diffuse inflammatory reaction focused around the anterior residual lens capsule. The patient underwent surgical removal of the residual capsule and primary vitrectomy repair of the eye, achieving a significant improvement in visual symptoms and recovery of visual and anatomic function.




\section{Case Reports in Ophthalmology}

\section{Introduction}

Lens-induced uveitis, also called phacoantigenic uveitis or endophthalmitis phacoanaphylactica, is an inflammatory response to lens protein matter release into the eye which generates an autoimmune phenomenon in response to the presence of antigens the body does not recognize. It usually occurs as a result of surgery or eye trauma. It was first described by Straub [1] in 1919, and then Verhoeff and Lemoine [2] further expanded on this notion. Although this concept was not entirely accurate due to the limited knowledge of the pathology [3], endophthalmitis phacoanaphylactica became more of an "umbrella term" used to describe these symptoms.

We describe an unusual case of lens-induced uveitis developing 40 years after congenital cataract surgery that was induced by intravitreal injections.

\section{Case Report/Presentation}

A 42-year-old male patient was referred for a follow-up after repair of a retinal detachment with proliferative vitreoretinopathy of the right eye. The patient has an ocular history of bilateral congenital cataract surgery at the age of 2 years, bilateral secondary glaucoma, and a general history of type I diabetes and hypercholesterolemia. During the first examination, the patient presented with intraocular pressures (IOP) of 10 and $17 \mathrm{~mm} \mathrm{Hg}$ in the right and left eye, respectively, measured by Goldmann applanation tonometer, under dorzolamide hydrochloride-timolol maleate and latanoprost drops. His visual acuity (VA) was sc1/200 in the right eye and 20/20 in the left eye. The ophthalmological exam in the right eye showed band keratopathy and aphakia with prephtisical globe as a complication of his past cataract surgery repair; in the left eye it showed aphakia with superotemporal Soemmering ring (Fig. 1), and the rest of the ophthalmological exam was normal. The recommendation for the patient at this time was to observe every 6 months.

The patient remained stable until 6 years later, when he developed moderate nonproliferative diabetic retinopathy in both eyes with cystoid diabetic macular edema in the left eye confirmed by SD-OCT of the macula with VA of 20/50. Intravitreal bevacizumab was administered starting at 6-week intervals but then shortened to 4 weeks. Because of the lack of improvement, the bevacizumab intravitreal injection was switched to triamcinolone acetonide. At this point he received a total of five bevacizumab intravitreal injections with an interval of 4-5 weeks between each one. The 4-week follow-up visit after his first triamcinolone acetonide intravitreal injection (sixth intravitreal injection) showed that the VA reached 20/25 and there was evident improvement on the macular OCT. A day after his seventh intravitreal injection that consisted of bevacizumab given in the inferotemporal quadrant, he arrived as an emergency visit for sudden onset of ocular redness and photophobia of the left eye. The ophthalmological exam showed VA dropping to counting fingers at 1 foot with IOP $24 \mathrm{~mm} \mathrm{Hg}$, periocular injection, and an inflammatory reaction focused around the anterior residual lens capsule with spillover to the anterior and posterior segment. The patient presented with no pain and pseudo-endophthalmitis was suspected. Treatment was started with prophylactic moxifloxacin/gentamicin drops for 2 weeks, oral levofloxacin for 1 week, and topical steroids for 1 month. His ocular anatomy remained stable; however, it did not improve significantly. His baseline blood work which included CBC, ESR, and CRP results were within normal limits. As a result, he was taken to the operating room for vitrectomy a month after initial complications. During the surgery, the cataract remnant was surrounded by a thick brown 


\section{Case Reports in Ophthalmology}

Case Rep Ophthalmol 2020;11:293-298

DOI: 10.1159/000508390

c) 2020 The Author(s). Published by S. Karger AG, Basel www.karger.com/cop

El Hamichi et al.: Lens-Induced Uveitis 40 Years after Cataract Surgery

inflammatory tissue posterior to the iris; it was removed and biopsied (Fig. 2a, b). The vitreous tap and residual lens material were sent to pathology. Pathological results reported: lens material with focal calcification, focal globule formation, no inflammatory infiltrate noted, and negative for any infection. Intravitreal bevacizumab injections every 4 weeks were resumed 1 month after surgery with evidence of improvement with VA of 20/300, IOP $17 \mathrm{~mm} \mathrm{Hg}$, and OCT of the macula showing a reduction of macular edema.

\section{Discussion/Conclusion}

Phacoantigenic reaction could be responsible for pseudotumor presentation in the vitreous. In 1919, Straub [1] suggested that uveitis could be caused by the liberation of lens proteins. Verhoeff and Lemoine [2] further expanded on this notion that the release of lens protein into the anterior chamber of the eye could be the cause of severe intraocular inflammation. They further explained that clinical onset typically occurs anywhere from 1 to 14 days after the leakage of the lens proteins [4].

However, there are cases where the protein capsule has been ruptured without subsequent inflammatory responses [3]. In fact, these antigens present within the lens capsule have been found throughout the body, albeit in lower concentrations [5]. Regardless, the cause of phacoantigenic reactions is most commonly traumatic penetration of the lens capsule, often by surgery or other methods. Although the development of the inflammatory response occurs typically within a few days from the traumatic penetration or other events, years of being asymptomatic is not unheard of with a time frame of 59 years being reported [6].

In our case, the patient had bilateral congenital cataracts that were treated at the age of 2 years. Gross examination revealed residual lens material (Soemmering ring) from his surgical procedure, that had been stable for 40 years. Due to his development of diabetic macular edema, the patient was recommended to undertake intravitreal injections of bevacizumab and triamcinolone acetate. We postulate that these were symptoms of phacoantigenic reaction due to release of the lens proteins in the eye. These were encapsulated by fibrin and inflammatory cells and the administration of intravitreal injections triggered a biological disruption of this pseudocapsule and thus the direct exposition of cataract material inside the eye, 40 years after congenital cataract surgery. Although the intravitreal injection was always performed by the same ophthalmologist in the inferotemporal quadrant of the eye while the lens residual was superotemporal, the possibility of mechanical trauma cannot be entirely excluded.

Endophthalmitis has a similar presentation, but this was ruled out due to the patient's lack of improvement after antibiotic treatment and negative laboratory results after vitreous and cataract biopsy. Although most of lens-induced uveitis occurs after a traumatic or surgery event that disrupts the lens capsule [7], it can also occur in hypermature cataracts. These cataracts have cortical matter liquefaction, an accelerated lens fiber dissolution, and a small hard nucleus [8]. If left untreated, this could develop into phacolytic glaucoma or phacoanaphylactic uveitis [8]. Congenital cataracts may also be associated with lens-induced granulomatous uveitis in a newborn. Whereas granulomatous uveitis is usually caused by congenital infections, there are extremely rare cases where it can develop without such causation. Vandenbroucke et al. [9] reported a patient who may have developed uveitis due to the possibility of microscopic protein leakage causing lens-induced uveitis. Although our patient had congenital cataracts that formed and were treated prior to their phacoantigenic reaction episode, lensinduced uveitis may have played a role in their optical degeneration. 


\section{Case Reports in Ophthalmology}

El Hamichi et al.: Lens-Induced Uveitis 40 Years after Cataract Surgery

This case emphasizes the two important points. The first of these is the necessity of further research into the causes of phacoantigenic reactions. The possibility may, in fact, not be due to an immunological response to the lens protein leakage as previously thought, but instead could be caused by altered tolerance in the human body to lens proteins [5]. Furthermore, recent studies suggested that the brain and the eye - like the rest of the body organs are provided by lymphatic drainage system and immune surveillance. Nonetheless, they are subject to immune quiescence mechanisms rather than the concept of immune privilege as previously believed [10-14]. The second point is the understanding of the side effects of intravitreal injections, as there is a possibility of this case being a sterile endophthalmitis secondary to intravitreal injections. Studies have reported ocular inflammatory responses occurring after triamcinolone acetonide and bevacizumab injections [15-18]. The possibility of combined mechanism cannot be excluded in our case; however, the slow improvement after topical steroid treatment and the favorable outcome after lens material removal is highly suggestive of lens-induced uveitis.

\section{Acknowledgments}

We would like to thank Belinda Rodriguez, photographer, for providing this case with images and editing the video.

\section{Statement of Ethics}

This case report was conducted in accordance with the Declaration of Helsinki. The collection and evaluation of all protected patient health information was performed in a Health Insurance Portability and Accountability Act (HIPAA)-compliant manner.

Informed consent was obtained prior to performing the procedure including permission for the publication of photographs and images included herein.

\section{Conflict of Interest Statement}

The authors have no conflicts of interest to declare.

\section{Funding Sources}

This article was supported by NIH Center Core Grant P30EY014801, a Research to Prevent Blindness Unrestricted Grant.

\section{Author Contributions}

Sophia El Hamichi: acquisition, analysis, and interpretation of data; drafting the work. Rafael J. Aguilar: analysis and interpretation of data; drafting the work. Veronica Kon Graversen, Aaron S. Gold, and Audina M. Berrocal: design of the work; revising the work critically for 


\section{Case Reports in Ophthalmology}

\begin{tabular}{l|l}
\hline DOI: $10.1159 / 000508390$ & (c) 2020 The Author(s). Published by S. Karger AG, Basel
\end{tabular}
www.karger.com/cop

El Hamichi et al.: Lens-Induced Uveitis 40 Years after Cataract Surgery

important intellectual content. Timothy G. Murray: conception and design of the work; revising the work critically for important intellectual content.

\section{References}

1 Straub M. Inflammations of the eye caused by lenticular material dissolved in eye lymph. Amsterdam: J.H. De Bussy; 1919.

2 Verhoeff FH, Lemoine AN. Endophthalmitis phacoanaphylactica. Am J Ophthalmol. 1922;5:737-45.

3 Rajesh B, Hussain R, Gopalakrishnan M, Giridhar A. Phacoantigenic Reaction Masquerading as Postoperative Endophthalmitis in a Silicone Oil-filled Eye. Middle East Afr J Ophthalmol. 2016 Oct-Dec;23(4):318-20.

4 McMahon MS, Weiss JS, Riedel KG, Albert DM. Clinically unsuspected phacoanaphylaxis after extracapsular cataract extraction with intraocular lens implantation. Br J Ophthalmol. 1985 Nov;69(11):836-40.

5 Marak GE Jr. Phacoanaphylactic endophthalmitis. Surv Ophthalmol. 1992 Mar-Apr;36(5):325-39.

6 Thach AB, Marak GE Jr, McLean IW, Green WR. Phacoanaphylactic endophthalmitis: a clinicopathologic review. Int Ophthalmol. 1991 Jul;15(4):271-9.

7 Wirostko E, Spalter HF. Lens-induced uveitis. Arch Ophthalmol. 1967 Jul;78(1):1-7.

8 Dhingra D, Grover S, Kapatia G, Pandav SS, Kaushik S. Phacolytic glaucoma: A nearly forgotten entity. Eur J Ophthalmol. 2019 Apr;1120672119841972(April):1120672119841972.

9 Vandenbroucke S, Foets B, Wouters C, Casteels I. Bilateral congenital cataract with suspected lens-induced granulomatous uveitis. J AAPOS. 2014 Oct;18(5):492-4.

10 Nche EN, Amer R. Lens-induced uveitis: an update. Graefes Arch Clin Exp Ophthalmol. 2020 Jul;258(7):135965.

11 Aspelund A, Antila S, Proulx ST, Karlsen TV, Karaman S, Detmar M, et al. A dural lymphatic vascular system that drains brain interstitial fluid and macromolecules. J Exp Med. 2015 Jun;212(7):991-9.

12 Knickelbein JE, Buela KA, Hendricks RL. Antigen-presenting cells are stratified within normal human corneas and are rapidly mobilized during ex vivo viral infection. Invest Ophthalmol Vis Sci. 2014 Feb;55(2):1118-23.

13 Ransohoff RM, Engelhardt B. The anatomical and cellular basis of immune surveillance in the central nervous system. Nat Rev Immunol. 2012 Sep;12(9):623-35.

14 Shechter R, London A, Schwartz M. Orchestrated leukocyte recruitment to immune-privileged sites: absolute barriers versus educational gates. Nat Rev Immunol. 2013 Mar;13(3):206-18.

15 Jonisch J, Lai JC, Deramo VA, Flug AJ, Fastenberg DM. Increased incidence of sterile endophthalmitis following intravitreal preserved triamcinolone acetonide. Br J Ophthalmol. 2008 Aug;92(8):1051-4.

16 Marticorena J, Romano V, Gómez-Ulla F. Sterile endophthalmitis after intravitreal injections. Mediators Inflamm. 2012;2012:928123.

17 Chong DY, Anand R, Williams PD, Qureshi JA, Callanan DG. Characterization of sterile intraocular inflammatory responses after intravitreal bevacizumab injection. Retina. 2010 Oct;30(9):1432-40.

18 Georgopoulos M, Polak K, Prager F, Prünte C, Schmidt-Erfurth U. Characteristics of severe intraocular inflammation following intravitreal injection of bevacizumab (Avastin). Br J Ophthalmol. 2009 Apr;93(4):457-62. 


\section{Case Reports in Ophthalmology}

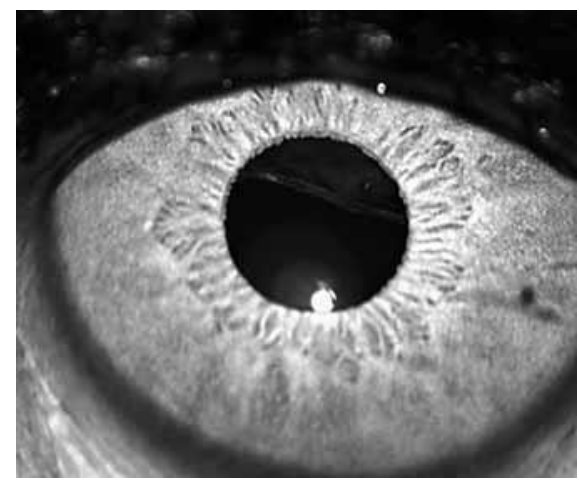

Fig. 1. Infrared photograph of the anterior segment of the left eye showing the residual lens material superiorly behind the iris.
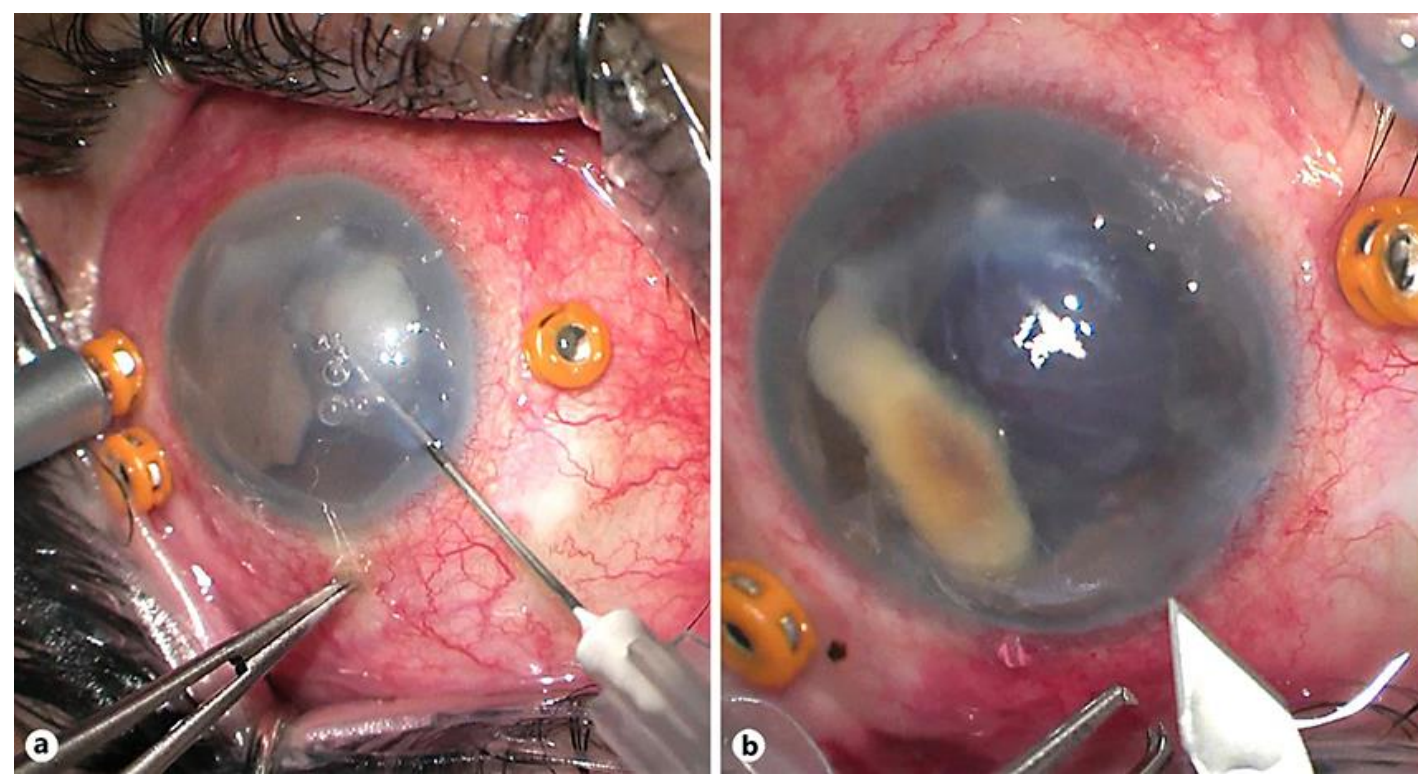

Fig. 2. a Snap picture from the surgery of the left eye showing the inflammation of the anterior segment with presence of brown material as well as the cataract remnants. $\mathbf{b}$ Snap picture from the surgery showing the cataract remnant after cleaning the anterior chamber inflammation. 